\title{
Pharmaceutical Care in Depression: A Survey of Stigma, Confidence, Attitudes, and Barriers
}

This article was published in the following Dove Press journal:

Risk Management and Healthcare Policy

\section{Moetaza Soliman (D)}

Department of Pharmacy Practice, Faculty of Pharmacy, Mansoura University, Mansoura, EIDakahlia, Egypt
Correspondence: Moetaza Soliman

Department of Pharmacy Practice, Faculty of Pharmacy, Mansoura University,

EIGomhoria Street, Mansoura, EIDakahlia,

Egypt

Email moetaza13@yahoo.com
Purpose: Patients with depression are in high need of optimal pharmaceutical care as they have poor quality of life and functioning. However, little is known about the delivery of pharmaceutical care to patients with depression in Egypt. This study aimed to detect pharmacists' stigma of patients with depression, assess attitudes toward providing depression care, evaluate pharmacists' confidence with depression medication consultation, and identify barriers in providing pharmaceutical care to patients with depression.

Methods: A cross-sectional survey was posted on the social media websites of Egyptian pharmacists' groups and associations. The survey collected pharmacists' demographic information, then measured their confidence in medication consultation through the Pharmacists' Confidence scale about Medication Consultation for Depressive Patients (PCMCD), with items to assess stigma of patients with depression and attitudes toward providing care to patients with depression compared with other physical conditions. The pharmacists were also asked about the barriers to providing pharmaceutical care to patients with depression.

Results: Totally, 86 pharmacists completed the survey: $56(65.1 \%)$ were aged 30 years or older, and $64(74.6 \%)$ had more than five years of experience. The stigma of patients with depression was generally low. The mean (SD) PCMCD score was 51.4 (6.6), reflecting that most pharmacists were confident about medication consultation for patients with depression. Attitudes toward providing pharmaceutical care to patients with depression were generally positive but significantly lower than those reported for patients with other conditions. Lack of education on mental health was the most commonly reported barrier $(81.2 \%)$ to providing pharmaceutical care to patients with depression.

Conclusion: Participants were confident about medication consultation with a positive attitude toward providing pharmaceutical care. Frequent mental health educational courses, tools, and other methods of consistent engagement that enhance practice, behaviors, and outcomes should be considered for Egyptian pharmacists to improve pharmaceutical care provided to patients with depression.

Keywords: PCMCD score, cross-sectional, Egyptian pharmacists, medication consultation

\section{Introduction}

Depression is a highly prevalent, serious, and recurrent public health issue that imposes limitations on quality of life and functioning. Major depression represents a leading global cause of disability. ${ }^{1}$ In Egypt, the prevalence of depressive disorders was $6.43 \%$ in adult population. ${ }^{2}$ Higher prevalence was reported in the elderly Egyptian population where the prevalence of depression among people aged 60 years or more was $44.4 \%{ }^{3}$

Patients with depression are subject to stigma. ${ }^{4}$ In Egypt, depression may be viewed as a personality weakness and laziness rather than an illness. ${ }^{5}$ Depression resulting in suicide is highly stigmatized in Egypt due to religious reasons. ${ }^{6}$ 
Families in Egypt tend to hide that they have a person with depression as they think this will bring discrimination and bad reputation to the family. ${ }^{7}$ This stigma associated with depression leads to delays in seeking treatment. ${ }^{7}$ Hence, those patients require extensive social and medical care.

Pharmacists with their knowledge, experience, and availability to patients are in a good position to take an active role in medical care for patients with depression. ${ }^{8}$ They are able to collect accurate medication history when directly questioning patients. ${ }^{9}$ In addition, most physicians are comfortable with pharmacists as a source of drug and disease information of patients with depression. ${ }^{10}$

In 1990, Hepler and Strand defined Pharmaceutical care as "the responsible provision of drug therapy for the purpose of achieving definite outcomes that improve a patient's quality of life". ${ }^{11}$ Pharmacists deliver patientcentered services, including taking medication history, monitoring for effectiveness and adverse effects of medication, screening for pharmacotherapy problems, and providing patient education and counseling. ${ }^{11,12}$ Although the dispensing pharmacist is still a common model in pharmacy practice in Egypt, great efforts have been made by the Egyptian Ministry of Health to speed up the implementation of clinical pharmacy services. A recent survey of 495 Egyptian pharmacists revealed that high percentages of American College of Clinical Pharmacy competencies were generally applied by Egyptian pharmacists. ${ }^{13}$ These competences included six essential domains; "pharmacotherapy knowledge, communication, direct patient care, systems-based care, continuing professional development, and professionalism". ${ }^{14}$

A study in the United Kingdom revealed the stigma of patients with mental illness by British adults, where patients were perceived as dangerous, unpredictable, and hard to communicate with. ${ }^{15}$ Health professionals including doctors and pharmacists showed stigma of patients with mental illnesses, including depression, schizophrenia, dementia, and drug addiction. ${ }^{16,17}$ The presence of the pharmacists' stigma of patients with mental illness may decrease the quality of pharmaceutical care services provided to those patients. ${ }^{18}$ Literature searches revealed no studies performed to see if there was a level of pharmacists' stigma to patients with depression in Egypt.

Medication consultations for patients with depression require pharmacists' interpersonal skills to understand patients' needs, build and maintain a trusting relationship with patients. Other professional skills would resolve and intervene in poor medication adherence to increase adherence rates, provide information about proper administration of medications, advise on dealing with medications' side effects, and relieve anxiety about medications. ${ }^{19-21}$ Building a trust relationship with patients facilitates patient history-taking, as patients tend to freely talk to their pharmacists if there is an established trust relationship. ${ }^{22}$ Poor medication adherence is a very common problem among patients with depression because of lack of interest and hope created by the disease itself. ${ }^{23,24}$ Educating patients during counseling sessions about their disease, medications, and dealing with side effects improves adherence to medication and overall outcomes of the patients. ${ }^{25,26}$ No studies in the literature assessed pharmacists' confidence about medication consultations for patients with depression in Egypt.

Previous studies revealed that pharmacists' attitudes toward providing care to patients with mental disorders such as depression and schizophrenia were lower than those seen in other physical illnesses such as hypertension, diabetes $^{27}$ or asthma. ${ }^{28}$ Pharmacists' poor attitude toward providing pharmaceutical care to patients with mental illness may decrease the efficiency of pharmaceutical care services presented to these patients. ${ }^{16,29}$ However, willingness to counsel patients with mental illness had greater value even by pharmacists with a low attitude to provide care to patients with depression or schizophrenia. ${ }^{28}$

From the pharmacists' perspective, there are many barriers to providing pharmaceutical care for depression. Pharmacist-related barriers might include lack of education, training, and experience in mental health. ${ }^{27}$ Patientrelated barriers might include lack of interest in learning about the disease or medications, and environmentalrelated barriers might include lack of time for individual consultations and lack of privacy in the pharmacy. ${ }^{29}$ Resolving these barriers would help increase the quality of services provided to patients with depression in the future. ${ }^{30}$

To our knowledge, no studies have reported on real-life pharmaceutical care for depression in Egypt. Thus, our study aimed to report on pharmaceutical care given to patients with depression in Egypt, focusing on the detection of stigma of patients with depression, assessment of attitudes toward providing depression care, evaluation of pharmacists' confidence with medication consultation on depression, and identification of barriers in providing pharmaceutical care to patients with depression from the pharmacists' perspective. This investigation is consistent with the general aim of full implementation of clinical pharmacy practice services in Egypt. Understanding the 
concerns and challenges of the pharmacists will improve the delivery of care to patients with depression.

\section{Methods}

\section{Study Design}

An online cross-sectional survey was developed. The survey was posted on the social media websites of Egyptian pharmacists' groups and associations for pharmacists' participation. The survey collected responses from June 1 to July 15, 2020. To be included in the study, the pharmacist had to be a registered pharmacist legally allowed to practice pharmacy in Egypt and had to provide informed consent for participation in the study. The survey contained two sections. The first section informed participating pharmacists about the study and collected demographic information using 11 closed-end questions. Demographic information included age, gender, years of practice, highest degree awarded in pharmacy, area of practice, and setting of practice (community, hospital, or other). This section also collected data on whether pharmacists received any postgraduate mental health training, whether the pharmacist or someone close to him/her suffers from depression, whether the pharmacist's opinions about depression affect his or her ability to provide pharmaceutical care to patients with depression, the estimated percentage of the pharmacist's patients suffering from depression, and if the pharmacy routinely screens patients for depression with a standard validated screening tool.

Using 28 Likert-scale questions and 2 closed-end questions, the second section collected the data using assessment tools of the study, namely, (i) pharmacists' stigma of patients with depression, (ii) pharmacists' confidence about medication consultation for patients with depression, (iii) pharmacists' attitudes toward providing pharmaceutical care to patients with depression, and (iv) barriers in providing care for patients with depression and pharmacists' needs for caring for patients with depression.

\section{Assessment Tools}

\section{Pharmacists' Stigma of Patients with Depression}

The pharmacists' stigma of patients with depression was assessed using items that were developed and validated in a national survey in the UK. ${ }^{15}$ The assessment involved eight items that measure how patients with depression are perceived, such as being dangerous to others, unpredictable, hard to talk to, different, having only themselves to blame, able to pull themselves together, and having poor response to treatments. The pharmacists responded to each item on a 5-point scale ranging from (1 - strongly agree) to (5 - strongly disagree). The response to each item was classified as "having negative opinions" if the pharmacist scored 1 or 2 . The responses to items were not summed.

\section{Pharmacists' Confidence About Medication Consultation for Patients with Depression}

The Pharmacists' Confidence scale about Medication Consultation for Depressive Patients (PCMCD) was created and validated in $2019 .{ }^{19}$ It consists of 12 items that measure pharmacists' confidence in providing specific medication consultation to patients with depression. The questionnaire covers five main aspects in medication consultation: (i) understanding the patients' background and relieving the patients' anxiety about medication; (ii) building and maintaining trust relationships with patients; (iii) understanding their medical condition and comorbid illnesses; (iv) counseling on methods of administration and dealing with side effects, and (v) assessment and management of patients' adherence to the medications. Each participant responded to each item on a 5-point scale ranging from (1) "total disagreement" to (5) "total agreement" that he/she could perform the task in the item. This generated a total score ranging from 12 to 60 . Higher scores suggested higher levels of pharmacists' confidence in providing consultations.

\section{Pharmacists' Attitudes Toward Providing Pharmaceutical Care to Patients with Depression}

Pharmacists' attitudes toward providing pharmaceutical care to patients with depression were assessed using questions adapted from a previous study by Cates et al $2005 .{ }^{31}$ The questions measured how pharmacists were interested, comfortable, confident, and likely to perform pharmaceutical care tasks. The tasks included taking medication history, screening for drug-related problems, monitoring for effectiveness and adverse effects of medication, and providing medication counseling. Since those tasks were not specific to depression care, attitudes toward providing pharmaceutical care to patients other than those with depression were also measured for comparison. Pharmacists responded to each question with "much more", "more", "neutral", "less", or "much less."

\section{Barriers in Providing Care for Patients with Depression and Pharmacists' Needs for Caring for Patients with Depression}

Pharmacists identified possible barriers in providing pharmaceutical care to patients with depression. A list of 
barriers was selected from previously identified possible barriers in the literature. ${ }^{27,29,30}$ Pharmacists were allowed to choose as many barriers as they thought relevant. They were also asked to indicate their needs to improve services provided to patients with depression from a list of previously identified needs in the literature. ${ }^{29}$

\section{Statistical Analysis}

Descriptive statistics were used to describe the pharmacists' information. The response to questions was presented as mean \pm standard deviation (SD) for continuous data or frequency distributions for discrete data. The PCMCD score was calculated by summing the response to the 12 items for each pharmacist, and its internal consistency was checked using Cronbach's $\alpha$ coefficient (Cronbach's $\alpha$ coefficient $>0.7$ was considered acceptable). ${ }^{32}$ Pharmacists' attitudes toward providing pharmaceutical care to patients with depression and other physical illnesses were compared using the Wilcoxon signed-rank test. The $p$-values $<0.05$ were considered significant. Stata 10.1 software was used for all statistical analyses (Stata Corp., College Station, TX, USA).

\section{Ethical Approval}

Ethical approval for the study was granted by the Mansoura University Ethical Committee before the commencement of any data collection from pharmacists. All participating pharmacists provided informed consent, and the study was in compliance with the Declaration of Helsinki 1975, as revised in 2000.

\section{Results}

\section{Demographic Information}

In total, 89 pharmacists participated in the survey; three of them were excluded because of missing data. The demographic information of the 86 pharmacists included in the analysis is presented in Table 1. About one-third of the participating pharmacists were men, three quarters were 40 years old or younger, and three quarters had more than five years of experience. About half of the pharmacists were practicing in a community pharmacy setting. They were practicing in different regions in Egypt; 33 (38.8\%) were practicing in the Delta Region, while 28 (32.9\%) were practicing in Greater Cairo. About $46.5 \%$ of the participating pharmacists had a postgraduate degree in pharmacy; however, $81.0 \%$ of them declared that they did not receive any educational course or training on mental health. The majority of pharmacies (96.5\%) did not routinely screen patients for depression with a standard validated screening tool. The estimated percentage of
Table I Demographic Information of Pharmacists Surveyed $(n=86)$

\begin{tabular}{|c|c|}
\hline Characteristics & n (\%) \\
\hline \multicolumn{2}{|l|}{ Age (year) } \\
\hline$<30$ & $30(34.9)$ \\
\hline $30-40$ & $34(39.5)$ \\
\hline $4 I-50$ & $18(20.9)$ \\
\hline$>50$ & $4(4.7)$ \\
\hline \multicolumn{2}{|l|}{ Gender } \\
\hline Male & $26(30.2)$ \\
\hline Female & $60(69.8)$ \\
\hline \multicolumn{2}{|l|}{ Years of practice (year) } \\
\hline$<5$ years & $22(25.6)$ \\
\hline 5 to 10 years & $26(30.2)$ \\
\hline II to 20 years & $26(30.2)$ \\
\hline$>20$ years & $12(14.0)$ \\
\hline \multicolumn{2}{|l|}{ Setting of pharmacy practice } \\
\hline Community pharmacy & $43(50.6)$ \\
\hline Hospital pharmacy & $26(30.6)$ \\
\hline Other & $16(18.8)$ \\
\hline \multicolumn{2}{|l|}{ Region of practice } \\
\hline Greater Cairo & $28(32.9)$ \\
\hline Alexandria region & $17(20.0)$ \\
\hline Delta Region & $33(38.8)$ \\
\hline Upper Egypt & $8(9.3)$ \\
\hline \multicolumn{2}{|l|}{ Highest degree awarded in pharmacy } \\
\hline B Pharm & $46(53.5)$ \\
\hline Diploma & $17(19.8)$ \\
\hline Pharm D & $10(11.6)$ \\
\hline Master & $8(9.3)$ \\
\hline $\mathrm{PhD}$ & $5(5.8)$ \\
\hline \multicolumn{2}{|l|}{$\begin{array}{l}\text { Pharmacist received any postgraduate mental } \\
\text { health training }\end{array}$} \\
\hline No & $68(81.0)$ \\
\hline Yes & $16(19.0)$ \\
\hline \multicolumn{2}{|l|}{$\begin{array}{l}\text { Pharmacist or someone close to him/her suffer } \\
\text { from depression }\end{array}$} \\
\hline No & $40(46.5)$ \\
\hline Yes & $46(53.5)$ \\
\hline \multicolumn{2}{|l|}{$\begin{array}{l}\text { Pharmacy routinely screen patients for } \\
\text { depression }\end{array}$} \\
\hline No & $83(96.5)$ \\
\hline Yes & $3(3.5)$ \\
\hline \multicolumn{2}{|l|}{$\begin{array}{l}\text { Estimated percentage of pharmacist's patients } \\
\text { suffering from depression }\end{array}$} \\
\hline 0 to $25 \%$ & $49(59.0)$ \\
\hline $26 \%$ to $50 \%$ & $25(30.1)$ \\
\hline $51 \%$ to $75 \%$ & $9(10.8)$ \\
\hline $76 \%$ to $100 \%$ & $0(0.0)$ \\
\hline
\end{tabular}

(Continued) 
Table I (Continued).

\begin{tabular}{|l|l|}
\hline Characteristics & $\mathbf{n}(\%)$ \\
\hline The pharmacist's ability to provide & \\
pharmaceutical care to depressed patients is & \\
affected by pharmacist's opinions about & \\
depression & \\
Definitely & $23(27.1)$ \\
Probably & $35(41.2)$ \\
Maybe & $16(18.8)$ \\
Not at all & $11(12.9)$ \\
\hline
\end{tabular}

pharmacists' patients with depression ranged from $0 \%$ to $25 \%$ in $49(59.0 \%)$ pharmacies and from $26 \%$ to $50 \%$ in $25(30.1 \%)$ pharmacies. About half of the pharmacists or someone close to them (53.5\%) suffered from depression, and 23 (27.1\%) pharmacists thought that their opinions about depression definitely affected their ability to provide pharmaceutical care to patients with depression.

\section{Pharmacists' Stigma of Patients with Depression}

The responses to each stigma item are presented in Table 2 . The number of pharmacists with negative opinions about patients with depression was high in response to items of "Patients with depression feel different" [74 (86.0\%)] and "Patients with depression are unpredictable" [52 (60.5\%)]. However, low proportions of pharmacists had negative opinions on items of "Patients with depression have only themselves to blame" [1 (1.2\%)] and "Patients with depression will never recover" [2 (2.3\%)]. In contrast, most pharmacists had positive opinions about the treatability and recovery of patients and that the patients should not be blamed for their disorder.

\section{Pharmacists' Confidence About Medication Consultation for Patients with Depression}

The internal consistency of the PCMCD score was acceptable (Cronbach's $\alpha$ coefficient of 0.80 ). The mean (SD) PCMCD score was 51.4 (6.6), and it ranged from 32 to 60 , reflecting that most participating pharmacists were confident about medication consultation for patients with depression. The responses to each item on the PCMCD are presented in Table 3. Most pharmacists reported that they agreed or tended to agree that they could ease patients' anxiety about their medication (mean [SD], 4.6 [0.7]), where 59 (68.6\%) pharmacists agreed, and 20 (23.3\%) tended to agree with the ability to perform the task. Respondents indicated much less confidence regarding informing the patients what to do when a side effect develops than other tasks [mean (SD) of $3.9(1.3)$ ].

\section{Pharmacists' Attitudes Toward Providing Pharmaceutical Care to Patients with Depression}

Pharmacists' attitudes toward providing pharmaceutical care to patients with depression and other patients (other than patients with depression) were generally positive (Table 4). However, less positive attitudes were reported toward providing pharmaceutical care to patients with depression than those reported for other conditions ( $\mathrm{P}<0.05$ for all items except for monitoring of efficacy and adverse effects where pharmacists showed similar

Table 2 Pharmacists' Stigma of Patients with Depression $(n=86)$

\begin{tabular}{|c|c|c|c|c|c|c|c|}
\hline \multirow[t]{2}{*}{ Item } & \multirow{2}{*}{$\begin{array}{l}\text { Mean } \pm \\
\text { SD }\end{array}$} & \multicolumn{5}{|c|}{ Response to Each Item, n (\%) } & \multirow{2}{*}{$\begin{array}{l}\text { Having } \\
\text { Negative } \\
\text { Opinion, } \\
\text { n (\%) }\end{array}$} \\
\hline & & $\begin{array}{l}\text { Strongly } \\
\text { Agree }\end{array}$ & Agree & Neutral & Disagree & $\begin{array}{l}\text { Strongly } \\
\text { Disagree }\end{array}$ & \\
\hline Patients with depression are dangerous to others & $3.2 \pm 1.1$ & $8(9.3)$ & $10(11.6)$ & $34(39.5)$ & $23(26.7)$ & II (12.8) & $18(20.9)$ \\
\hline Patients with depression are unpredictable & $2.3 \pm 1.0$ & $22(25.6)$ & $30(34.9)$ & $21(24.4)$ & $12(14.0)$ & $\mathrm{I}(\mathrm{I} .2)$ & $52(60.5)$ \\
\hline Patients with depression are hard to talk to & $3.2 \pm 1.2$ & $7(8.1)$ & $20(23.3)$ & $24(27.9)$ & $21(24.4)$ & $14(16.3)$ & $27(31.4)$ \\
\hline Patients with depression feel different & $1.7 \pm 0.8$ & $39(45.3)$ & $35(40.7)$ & $9(10.5)$ & $2(2.3)$ & $\mathrm{I}(\mathrm{I} .2)$ & $74(86.0)$ \\
\hline Patients with depression have only themselves to blame & $4.6 \pm 0.7$ & $0(0.0)$ & I (I.2) & $6(7.0)$ & $23(26.7)$ & $56(65.1)$ & I (1.2) \\
\hline Patients with depression should pull themselves together & $3.4 \pm 1.4$ & $11(12.9)$ & $12(14.1)$ & $19(22.4)$ & $20(23.5)$ & $23(27.1)$ & $23(27.1)$ \\
\hline Patients with depression are not improved if treated & $4.3 \pm 1.2$ & $7(8.1)$ & $2(2.3)$ & $3(3.5)$ & $19(22.1)$ & $55(64.0)$ & $9(10.5)$ \\
\hline Patients with depression will never recover & $4.5 \pm 0.7$ & $0(0.0)$ & $2(2.3)$ & $5(5.8)$ & $26(30.2)$ & $53(61.6)$ & $2(2.3)$ \\
\hline
\end{tabular}

Notes: The pharmacists responded to each item on a 5-point scale ranging from ( 1 - strongly agree) to (5 - strongly disagree). The response to each item is classified as "having negative opinions" if the pharmacist scored I or 2. 
Table 3 Pharmacists' Confidence About Medication Consultation for Depressive Patients (PCMCD) ( $n=86)$

\begin{tabular}{|c|c|c|c|c|c|c|}
\hline \multirow[t]{2}{*}{ Item } & \multirow{2}{*}{$\begin{array}{l}\text { Mean } \pm \\
\text { SD }\end{array}$} & \multicolumn{5}{|l|}{ n (\%) } \\
\hline & & Disagree & $\begin{array}{l}\text { Tend to } \\
\text { Disagree }\end{array}$ & $\begin{array}{l}\text { Neither } \\
\text { Agree Nor } \\
\text { Disagree }\end{array}$ & $\begin{array}{l}\text { Tend to } \\
\text { Agree }\end{array}$ & Agree \\
\hline I can understand the patient's medical condition & $4.1 \pm 1.0$ & $3(3.5)$ & $6(7.0)$ & $8(9.3)$ & $33(38.4)$ & 36 (41.9) \\
\hline I can perceive change in the patient's medical condition & $4.0 \pm 1.2$ & $6(7.0)$ & $6(7.0)$ & $8(9.3)$ & $30(34.9)$ & $36(41.9)$ \\
\hline I can comprehend the patient's comorbid illness & $4.1 \pm 1.1$ & $5(5.8)$ & $4(4.7)$ & $7(8.1)$ & $27(31.4)$ & $43(50.0)$ \\
\hline I can ease the patient's anxiety about medication & $4.6 \pm 0.7$ & $0(0.0)$ & $3(3.5)$ & $4(4.7)$ & $20(23.3)$ & $59(68.6)$ \\
\hline I can understand the patient's background and value system. & $4.4 \pm 0.8$ & $0(0.0)$ & $3(3.5)$ & $5(5.8)$ & $32(37.2)$ & $46(53.5)$ \\
\hline I can comprehend the patient's medication adherence status & $4.2 \pm 1.0$ & $2(2.3)$ & $5(5.8)$ & II (12.8) & $24(27.9)$ & $44(5 । .2)$ \\
\hline I can establish a trust relationship with the patient & $4.3 \pm 1.0$ & $3(3.5)$ & $2(2.3)$ & II (I2.8) & $22(25.6)$ & $48(55.8)$ \\
\hline I can maintain a good trust relationship with the patient & $4.3 \pm 0.9$ & $2(2.3)$ & $2(2.3)$ & II (I2.8) & $24(27.9)$ & $47(54.7)$ \\
\hline I can tell what to do when a side effect develops & $3.9 \pm 1.3$ & $7(8.1)$ & $8(9.3)$ & $5(5.8)$ & $30(34.9)$ & $36(4 I .9)$ \\
\hline I can provide information on side effects of antidepressants & $4.5 \pm 0.9$ & $2(2.3)$ & $\mathrm{I}(\mathrm{l} .2)$ & $5(5.8)$ & $21(24.4)$ & $57(66.3)$ \\
\hline I can appropriately instruct how to take antidepressants & $4.5 \pm 0.9$ & $2(2.3)$ & $2(2.3)$ & $5(5.8)$ & $19(22.1)$ & $58(67.4)$ \\
\hline $\begin{array}{l}\text { I can provide guidance to patients with poor medication } \\
\text { adherence }\end{array}$ & $4.5 \pm 0.6$ & $0(0.0)$ & I (I.2) & $4(4.7)$ & $33(38.4)$ & $48(55.8)$ \\
\hline Total score & $51.4 \pm 6.6$ & - & - & - & - & - \\
\hline
\end{tabular}

Notes: Each participant responded to each item on a 5-point scale ranging from (I) "total disagreement" to (5) "total agreement" that he/she can perform the task in the item.

attitudes in depression and other physical conditions). For patients with depression, obtaining medication history received much less positive attitude compared to other pharmaceutical care tasks, where 54 (62.8\%) pharmacists reported being more or much more interested, comfortable, confident, and likely to obtain medication history.

\section{Barriers in Providing Care for Patients with Depression and Pharmacists' Needs for Caring for Patients with Depression}

Barriers to providing pharmaceutical care to patients with depression are presented in Figure 1. From the pharmacists' perspective, lack of education on mental health $(81.2 \%)$ was the most commonly reported barrier in providing pharmaceutical care to patients with depression, followed by lack of time for individual consultation $(57.5 \%)$ and lack of a private area in the pharmacy to allow discussion of personal issues (56.6\%). Insufficient valorization of providing pharmaceutical care services to patients $(23.5 \%)$ was the least commonly reported barrier.

The pharmacists' needs for caring for patients with depression are presented in Figure 2. An educational course covering mental health was needed by $82.2 \%$ of the pharmacists, while $68.6 \%$ of the pharmacists required training on patient participation techniques.

\section{Discussion}

From the pharmacists' perspective, this study reported on the current practice of pharmaceutical care provided to patients with depression in Egypt. Multidimensional aspects were investigated, including detection of pharmacists' stigma of patients with depression, assessment of pharmacists' attitudes toward providing care for depression compared to care for other physical illnesses, assessment of pharmacists' confidence about medication consultations, and identification of possible barriers to providing care.

Egyptian pharmacists' stigma of patients with depression was generally low. However, in only two items, higher proportions (95\% confidence intervals) of pharmacists had negative opinions about patients with depression. For example, 86.0\% (78.6-93.5) of the surveyed pharmacists agreed or strongly agreed that patients with depression feel different compared to 77.7 (74.1-81.3) among British doctors and medical students, ${ }^{33} 42.6$ (40.0-45.2) among British general public, ${ }^{10}$ 39.3 (33.0-45.6) among Australian pharmacists, ${ }^{16}$ and 35.4 (29.0-41.8) among Australian pharmacy students. ${ }^{16}$ Proper interventions should be considered to decrease pharmacists' stigma to depression patients, even further, to improve the quality of care presented to this group of patients.

Egyptian pharmacists were confident about medication consultation for patients with depression, with a mean 
Table 4 Pharmacists' Attitudes Toward Providing Pharmaceutical Care to Patients with Depression and Other Physical Conditions $(n=86)$

\begin{tabular}{|c|c|c|c|}
\hline \multirow[t]{2}{*}{ Task } & \multicolumn{2}{|c|}{ Response, n (\%) ${ }^{\dagger}$} & \multirow[t]{2}{*}{$P$ value } \\
\hline & Depression & $\begin{array}{l}\text { Other Physical } \\
\text { Conditions }\end{array}$ & \\
\hline \multicolumn{4}{|c|}{$\begin{array}{l}\text { How confident, comfortable, interested, and likely are you to } \\
\text { obtain a medication history? }\end{array}$} \\
\hline Much less & $2(2.3)$ & $0(0.0)$ & 0.0000 \\
\hline Less & $5(5.8)$ & $5(5.8)$ & \\
\hline Neutral & $25(29.1)$ & $10(11.6)$ & \\
\hline More & $39(45.3)$ & $38(44.2)$ & \\
\hline Much More & $15(17.4)$ & $33(38.4)$ & \\
\hline
\end{tabular}

How confident, comfortable, interested, and likely are you to screen for pharmacotherapy problems?

\begin{tabular}{l|l|l|l|}
\hline Much less & $I(I .2)$ & $0(0.0)$ & 0.0005 \\
Less & $3(3.5)$ & $4(4.7)$ & \\
Neutral & $24(28.2)$ & $12(14.0)$ & \\
More & $37(43.5)$ & $37(43.0)$ & \\
Much More & $20(23.5)$ & $33(38.4)$ & \\
\hline
\end{tabular}

How confident, comfortable, interested, and likely are you to monitor for efficacy and adverse effects?

\begin{tabular}{l|l|l|l|}
\hline Much less & $3(3.5)$ & I (I.2) & 0.57 \\
Less & $1(1.2)$ & $4(4.7)$ & \\
Neutral & $18(20.9)$ & $13(15.1)$ & \\
More & $36(41.9)$ & $45(52.3)$ & \\
Much More & $28(32.6)$ & $23(26.7)$ & \\
\hline
\end{tabular}

How confident, comfortable, interested, and likely are you to provide medication counseling?

\begin{tabular}{|l|l|l|l|} 
Much less & $0(0.0)$ & $0(0.0)$ & 0.003 \\
Less & $7(8.1)$ & $4(4.7)$ & \\
Neutral & $15(17.4)$ & $6(7.0)$ & \\
More & $36(41.9)$ & $37(43.0)$ & \\
Much More & $28(32.6)$ & $39(45.3)$ & \\
\hline
\end{tabular}

Notes: 'Pharmacists responded to each question with "much more", "more", "neutral", "less", or "much less." ${ }^{\prime}$ Attitudes to patients with depression and other physical illnesses were compared using the Wilcoxon signed-rank test. The p-values $<0.05$ were considered significant.

(95\% CI) PCMCD score of 51.4 (50.0-52.8), which was higher than the mean PCMCD score of 33.5, as reported in a study of 77 Japanese pharmacists. ${ }^{19}$ Despite the presence of low levels of stigma of patients with depression, Egyptian pharmacists appeared to be confident about their capabilities in dealing with patients with depression. Future studies evaluating the satisfaction of patients with depression on pharmaceutical care provided to them are needed to ascertain pharmacists' confidence as being effectively translated to the benefit of patients.
Egyptian pharmacists' attitudes were generally positive, as they were interested, comfortable, confident, and likely to perform different tasks in pharmaceutical care. Similar results were reported in the literature. ${ }^{29,31}$ However, Egyptian pharmacists' attitudes toward providing pharmaceutical care to patients with depression were lower compared to their attitude toward patients with other physical illnesses. This is in agreement with a study on 69 pharmacists from Belgium ${ }^{27}$ and a study on 187 pharmacists from Alabama, USA. ${ }^{31}$ Although pharmacists were confident in many skills working with patients with depression, they reported more negative attitudes toward providing care to patients with depression than physical illnesses. This factor could be explained by the presence of barriers to the delivery of care to patients with depression and the discrepancies between the ability to perform tasks and willingness to perform the task.

About $81.2 \%$ of pharmacists reported that lack of mental health education is a barrier to providing pharmaceutical care to patients with depression. This is in agreement with the study in Belgium. ${ }^{27}$ Although $46.5 \%$ of pharmacists had postgraduate degrees in pharmacy, only $19.0 \%$ of them received educational courses or training on mental health. This warrants the essential introduction of mental health education courses in pharmacy school curricula and/or the introduction of rotations related to mental health training during the implementation training programs provided to final year pharmacy students in Egypt.

Only $3.5 \%$ of the participating pharmacists reported routine screening of depression in patients at risk in pharmacies. A study from Bulgaria showed that pharmacists, as the most accessible health professionals, were able to detect mild to moderate depression in $55 \%$ of the tested patients. ${ }^{34}$ Early detection of depression is one of the pharmacists' roles in depression care. ${ }^{35}$ Screening for depression using suitable tools such as the Patient Health Questionnaire 2 (PHQ-2) and PHQ-7 is a task that should receive more attention within Egyptian pharmacists.

The key strengths of the current study include that it is the first to report on the current practice of pharmaceutical care in depression in Egypt. Pharmacists were surveyed on multiple parameters to assure the validity of the results. The study used a validated questionnaire with a total score to assess pharmacists' confidence about medication consultation; this can help compare with results from different studies or different participant groups. However, since the PCMCD was recently introduced (December 2019), few studies were available for comparisons. 


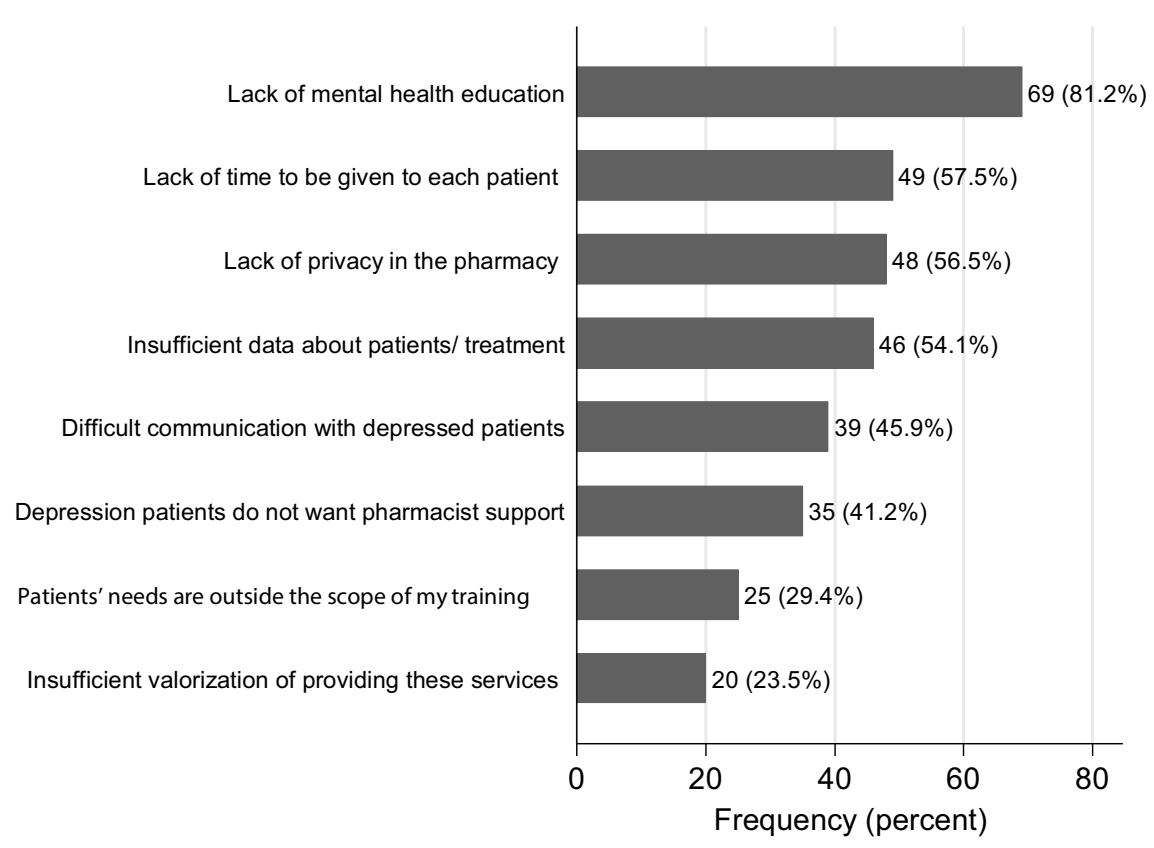

Figure I Barriers to provide pharmaceutical care to patients with depression $(n=86)$.

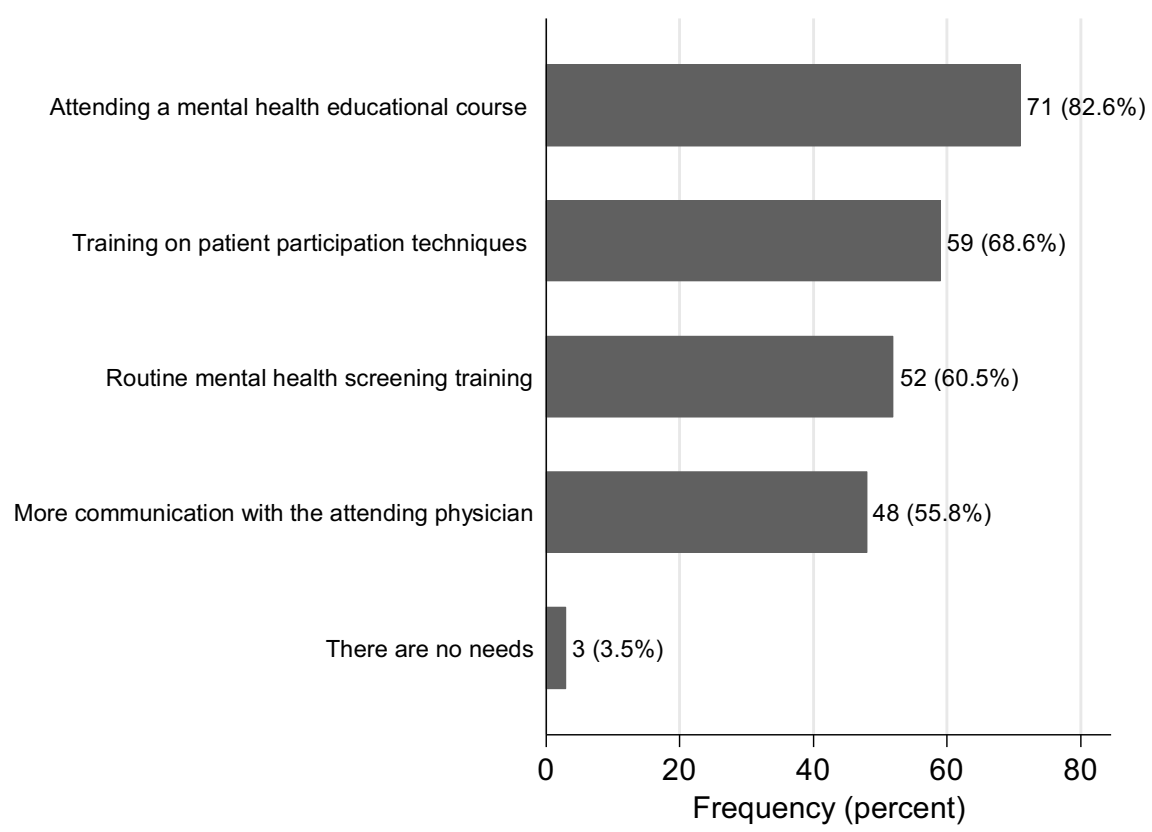

Figure 2 Pharmacists' needs for caring for patients with depression $(n=86)$.

The current study may be subject to selection bias, as pharmacists who were more concerned about patients with depression may have been more interested and likely to participate in the study. However, $46.5 \%$ of the pharmacists who participated in the study reported that neither they nor someone close to them suffered from depression, making them less sympathetic toward patients with depression. Selection bias may also be noted, as about two-thirds of the participating pharmacists were women which may be explained by the higher probability of women responding to survey studies in general. Women may be more positive and empathetic toward those with depression than men. However, responses were compared according to gender and according to whether pharmacists declared neither they nor someone close to them suffered from depression, and no significant differences were identified in both comparisons, suggesting less selection bias (supplementary material; Tables S1, S2, and S3). Another aspect of the study recruitment process that might affect who 
responded to the survey is the use of social media to distribute the survey. Pharmacists who use social media may have had different responses from those who do not.

The study methodology did not allow measurement of nonresponse bias. Pharmacists who did not respond to the survey may be less likely to have a positive attitude and practice dealing with patients with depression. However, since it was made clear that the survey was not collected by governmental authority, the non-response bias may be minimized.

Another limitation of the study may be the relatively small sample size and low response rate. Despite the survey being advertised in social media and in pharmacists' associations in every governorate in Egypt, only 89 pharmacists responded. However, respondents were from different regions in Egypt (Greater Cairo, Alexandria Region, Delta Region, and Upper Egypt) representing the entire country. The small sample size did not allow for studying factors that would have affected the response. The low response rate may be due to the absence of the culture taking part in questionnaires and surveys in pharmacist groups in Egypt, absence of rewards to participants, and refusal to be questioned on their duties, as they think they might be blamed for underperformance of the system. The lack of Egyptian pharmaceutical services assessment studies in the literature is evidence to support this theory. Encouragement and participation techniques such as rewarding the participants should be used in future similar studies.

Social desirability bias may be another limitation of the study since respondents may report what they think researchers want to see. The current study was based on pharmacists' perceptions and not their actions. A gap may exist between perceptions and actions, with perceptions being more positive than actual actions/performance of counseling behaviors. A future study of the evaluation of pharmacists' role in depression care from patients' perspectives would be of interest.

Finally, the current study was limited to the assessment of pharmaceutical care provided to patients with depression; however, other mental disorders such as schizophrenia, anxiety, and drug addiction warrant future assessments.

Future studies are needed to test the effectiveness of different interventions to decrease stigma of patients with depression or to increase the positive attitude toward providing care to patients with depression. The proper timing of these interventions needs to be studied at the undergraduate versus postgraduate level. The comparative effectiveness of introducing mental health education courses in pharmacy school curricula versus as rotations related to mental health could also be studied.
In conclusion, pharmacists' stigma of patients with depression was generally low. Pharmacists were confident about medication consultation with a generally positive attitude toward providing pharmaceutical care despite having less positive attitude toward patients with depression than toward patients with other physical illnesses. New actions and policies should be introduced to Egyptian pharmacists' education and training, such as frequent attendance of mental health educational courses, in both undergraduate and postgraduate settings. The content of mental health education courses is extensive; for example, warning signs of a suicide crisis, mental health first aid, and training on the use of depression screening tools with active participation of patients with mental illnesses in the courses. Other tools and methods of consistent engagement that enhance practice, behaviors, and outcomes should be considered for continuous support and education of pharmacists. This will help to decrease the stigma of patients with depression and improve the pharmaceutical care services provided to this group of patients.

\section{Acknowledgments}

The author would like to thank all Egyptian pharmacists who completed the survey. The author also thanks Professors Masaki Shoji, Atsuko Fujiwara, and Mitsuko Onda (Department of Social and Administrative Pharmacy, Osaka University of Pharmaceutical Sciences, Japan) for giving permission to use the "Pharmacists' Confidence scale about Medication Consultation for Depressive patients (PCMCD)" in this study.

\section{Funding}

There is no funding to report.

\section{Disclosure}

The author reports no conflicts of interest for this work.

\section{References}

1. Feigin V. Global, regional, and national incidence, prevalence, and years lived with disability for 310 diseases and injuries, 1990-2015: a systematic analysis for the global burden of disease study 2015. Lancet. 2016;388 (10053):1545-1602. doi:10.1016/S0140-6736(16)31678-6

2. Ghanem M, Gadallah M, Meky FA, Mourad S, El-Kholy G. National survey of prevalence of mental disorders in Egypt: preliminary survey. East Mediterr Health J. 2009;15(1):65-75.

3. El-Gilany A-H, Elkhawaga GO, Sarraf BB. Depression and its associated factors among elderly: a community-based study in Egypt. Arch Gerontol Geriatr. 2018;77:103-107. doi:10.1016/j.archger.2018.04.011

4. Kelly LS, Mckenna HP. Victimization of people with enduring mental illness in the community. J Psychiatr Ment Health Nurs. 1997;4 (3):185-191. doi:10.1046/j.1365-2850.1997.00054.x 
5. Okasha A. Expressed emotion, perceived criticism, and relapse in depression: a replication in an Egyptian community. Am J Psychiatry. 1994;151(7):1001-1005. doi:10.1176/ajp.151.7.1001

6. Aamer Sarfraz M, Castle DA. Muslim suicide. Australas Psychiatry. 2002;10(1):48-50. doi:10.1046/j.1440-1665.2002.00392.x

7. Endrawes G, O'Brien L, Wilkes L. Mental illness and Egyptian families. Int J Ment Health Nurs. 2007;16(3):178-187. doi:10.1111/ j.1447-0349.2007.00465.x

8. Bell S, McLachlan AJ, Aslani P, Whitehead P, Chen TF. Community pharmacy services to optimise the use of medications for mental illness: a systematic review. Aust New Zealand Health Policy. 2005;2(1):29. doi:10.1186/1743-8462-2-29

9. Gizzi LA, Slain D, Hare JT, Sager R. Assessment of a safety enhancement to the hospital medication reconciliation process for elderly patients. Am J Geriatr Pharmacother. 2010;8(2):127-135. doi:10.1016/j.amjopharm.2010.03.004

10. Ranelli PL, Biss J. Physicians' perceptions of communication with and responsibilities of pharmacists. J Am Pharm Assoc. 2000;40 (5):625-630. doi:10.1016/s1086-5802(16)31102-0

11. Hepler CD, Strand LM. Opportunities and responsibilities in pharmaceutical care. Am J Hosp Pharm. 1990;47(3):533-543.

12. Keely JL. Pharmacist scope of practice. Ann Intern Med. 2002;136 (1):79-85. doi:10.7326/0003-4819-136-1-200201010-00014

13. Elmaaty MA, Elberry AA, Hussein RR, Khalil DM, Khalifa AE. Applicability of American college of clinical pharmacy (ACCP) competencies to clinical pharmacy practice in Egypt. Pharm Pract (Granada). 2020;18(3):1951. doi:10.18549/PharmPract.2020.3.1951

14. Saseen JJ, Ripley TL, Bondi D, et al. ACCP clinical pharmacist competencies. Pharmacotherapy. 2017;37(5):630-636. doi:10.1002/ phar.1923

15. Crisp AH, Gelder MG, Rix S, Meltzer HI, Rowlands OJ. Stigmatisation of people with mental illnesses. $\mathrm{Br} J$ Psychiatry. 2000;177(1):4-7. doi:10.1192/bjp.177.1.4

16. Bell JS, Johns R, Chen TF. Pharmacy students' and graduates' attitudes towards people with schizophrenia and severe depression. Am J Pharm Educ. 2006;70(4):77. doi:10.5688/aj700477

17. Eksteen H-C, Becker PJ, Lippi G. Stigmatization towards the mentally ill: perceptions of psychiatrists, pre-clinical and post-clinical rotation medical students. Int $J$ Soc Psychiatry. 2017;63 (8):782-791. doi:10.1177/0020764017735865

18. Knaak S, Mantler E, Szeto A. Mental illness-related stigma in healthcare: barriers to access and care and evidence-based solutions. Healthc Manage Forum. 2017;30(2):111-116. doi:10.1177/0840470416679413

19. Shoji M, Fujiwara A, Onda M. Creation and validation of a semiquantitative instrument to assess the confidence of pharmacists in medication consultation for patients with depression: the pharmacists' confidence scale about medication consultation for depressive patients (PCMCD). Pharm Pract (Granada). 2019;17(4):1628. doi:10.18549/PharmPract.2019.4.1628

20. Kamusheva M, Ignatova D, Golda A, Skowron A. The potential role of the pharmacist in supporting patients with depression a literature-based point of view. Integr Pharm Res Pract. 2020;9:49-63. doi:10.2147/IPRP.S239672
21. Marques LAM, Galduroz JCF, Noto AR. Pharmaceutical care to patients treated with antidepressants. Rev Calid Asist Organo La Soc Esp Calid Asist. 2012;27(1):55-64. doi:10.1016/j.cali.2011.07.002

22. McCullough MB, Petrakis BA, Gillespie C, et al. Knowing the patient: a qualitative study on care-taking and the clinical pharmacist-patient relationship. Res Social Adm Pharm. 2016;12 (1):78-90. doi:10.1016/j.sapharm.2015.04.005

23. Rossom RC, Shortreed S, Coleman KJ, et al. Antidepressant adherence across diverse populations and healthcare settings. Depress Anxiety. 2016;33(8):765-774. doi:10.1002/da.22532

24. Kim S, Shin DW, Yun JM, et al. Medication adherence and the risk of cardiovascular mortality and hospitalization among patients with newly prescribed antihypertensive medications. Hypertension. 2016;67(3):506-512. doi:10.1161/HYPERTENSIONAHA.115.06731

25. Samples H, Mojtabai R. Antidepressant self-discontinuation: results from the collaborative psychiatric epidemiology surveys. Psychiatr Serv. 2015;66(5):455-462. doi:10.1176/appi.ps.201400021

26. Chong WW, Aslani P, Chen TF. Adherence to antidepressant medications: an evaluation of community pharmacists' counseling practices. Patient Prefer Adherence. 2013;7:813-825. doi:10.2147/ PPA.S48486

27. Scheerder G, De Coster I, Van Audenhove C. Pharmacists' role in depression care: a survey of attitudes, current practices, and barriers. Psychiatr Serv. 2008;59(10):1155-1160. doi:10.1176/ps.2008.59.10.1155

28. Rickles NM, Dube GL, McCarter A, Olshan JS. Relationship between attitudes toward mental illness and provision of pharmacy services. $J \mathrm{Am}$ Pharm Assoc (2003). 2010;50(6):704-713. doi:10.1331/JAPhA.2010. 09042

29. Al-Arifi MN. Community pharmacists attitudes towards mental illness and providing pharmaceutical care for mentally ill patients. Neurosciences (Riyadh). 2008;13(4):412-420.

30. Aaltonen SE, Laine NP, Volmer D, et al. Barriers to medication counselling for people with mental health disorders: a six country study. Pharm Pract (Granada). 2010;8(2):122-131. doi:10.4321/ s1886-36552010000200007

31. Cates ME, Burton AR, Woolley TW. Attitudes of pharmacists toward mental illness and providing pharmaceutical care to the mentally ill. Ann Pharmacother. 2005;39(9):1450-1455. doi:10.1345/aph.1G009

32. Morera OF, Stokes SM. Coefficient $\alpha$ as a measure of test score reliability: review of 3 popular misconceptions. Am J Public Health. 2016;106(3):458-461. doi:10.2105/AJPH.2015.302993

33. Mukherjee R, Fialho A, Wijetunge A, Checinski K, Surgenor T. The stigmatisation of psychiatric illness: the attitudes of medical students and doctors in a London teaching hospital. Psychiatr Bull. 2002;26 (5):178-181. doi:10.1192/pb.26.5.178

34. Kondova A, Todorova A, Tsvetkova A, Arnaoudova M, Andreevska KGD, Grekova D. Screening and risk assessment for depression in community pharmacy - pilot study. J IMAB. 2018;24 (1):1928-1931. doi:10.5272/jimab.2018241.1928

35. Rubio-Valera M, Chen TF, O'Reilly CL. New roles for pharmacists in community mental health care: a narrative review. Int J Environ Res Public Health. 2014;11(10):10967-10990. doi:10.3390/ijerph111010967
Risk Management and Healthcare Policy

\section{Publish your work in this journal}

Risk Management and Healthcare Policy is an international, peerreviewed, open access journal focusing on all aspects of public health, policy, and preventative measures to promote good health and improve morbidity and mortality in the population. The journal welcomes submitted papers covering original research, basic science, clinical \& epidemiological studies, reviews and evaluations, guidelines, expert opinion and commentary, case reports and extended reports. The manuscript management system is completely online and includes a very quick and fair peer-review system, which is all easy to use. Visit http://www.dovepress.com/testimonials.php to read real quotes from published authors. 